\title{
The retrieval of abstract and concrete materials as functions of imagery, mediation, and mnemonic aids*
}

\author{
FRANCIS J. DI VESTA and PHYLLIS M. SUNSHINE \\ Department of Educational Psychology, The Pennsylvania State University, University Park, Pennsylvania 16802
}

\begin{abstract}
This study is a report of an investigation of the interaction between imagery ability and processes employed for facilitating recall. The tasks were assumed to involve contrasting processes through the use of imaginal or verbal mediators and concrete or abstract jingles (mnemonic aids) in memorizing two concrete and two abstract lists of 10 words in each list. The dependent variables were latencies in arriving at an association, number of errors and omissions on immediate recall, and number of errors and omissions on delayed recall. The main effects of imagery ability, favoring high imagers, and of kind of lists favoring concrete lists were significant. In delayed recall there was a significant interaction of mnemonic aid and kind of list. Imagery ability interacted with mediators to influence Ss' recall. The results were discussed as supporting Paivio's two-stage association model.
\end{abstract}

Paivio (1969) has suggested that the learner, either because he has a preference for using images or because images are more available than words, tends to use an imagery strategy with concrete words. On the other hand, confronted with a task in which he is required to associate abstract terms, the learner employs a strategy emphasizing verbal association.

Of a number of experimental procedures used in tests of Paivio's theory, two were of concern in the present study. In one procedure, a jingle ("one is a bun," "two is a shoe," and so on) was employed as a mnemonic aid. Applied to the assumption in the aforegoing paragraph, it would be expected that a jingle consisting of concrete pegwords should facilitate the use of an imagery strategy; a jingle consisting of abstract pegwords should facilitate the use of a verbal strategy.

In another procedure, instructions were employed to induce the $S$ to use either an imagery or a verbal-associations strategy when learning the word pairs by use of a mnemonic device (Paivio \& Yuille, 1969). However, induction of treatments via instructions only may be a weak manipulation. Accordingly, the procedure was modified by Paivio and Foth (1970) by requiring the $\mathrm{S}$, in the imaginal-set treatment, to draw a picture linking the pegword to its serial counterpart in the list to be learned, and by requiring the $S$, in the verbal-set treatment, to write a sentence using the two words. These methodological variations provide means by which learner strategies can be manipulated. In terms of the initial assumption, it would be expected that imaginal sets would be more easily applied to concrete than to abstract materials, while verbal sets would be more effective for abstract materials than would imaginal sets.

In addition to examining the relation between recall

*The research reported in this paper was supported by the Advanced Research Projects Agency (ARPA Order No. 1269) through the Office of Naval Research under Contract ONR Nonr N00014-67-A-0385-006. and abstractness (or concreteness) of pegwords in mnemonic aids and between recall and mediational strategy, another purpose of the present study was to investigate the strategies employed by Ss with high or low imagery ability. In particular, it was expected that the forced use of an imaginal strategy would be compatible with the abilities of high imagers (thereby facilitating their recall) and incompatible with the abilities of low imagers (thereby hindering their recall). Furthermore, the assumption that abstract words are more easily associated to other words by verbal processes suggests that the performance of the low imagers would be especially hindered when forced to employ imaginal prczesses with the abstract mnemonic in learning an abstract list. Since little is known about which strategies low imagers employ or about ability of high imagers to use verbal strategies, specific hypotheses were not made for the two ability groups when using verbal strategies. Nevertheless, it was assumed intuitively that there would be no difference in the performance of the two groups or that high imagers would be at a slight disadvantage (Stewart, 1965).

The experiment reported here must be placed within the context of another study conducted by the present investigators. They had conducted an initial experiment, with $20 \mathrm{Ss}$ in each cell $(\mathrm{N}=160)$ of a design identical to the one reported here, to test the above assumptions. However, upon its completion it was apparent that some methodological problems might have confounded certain of the results. The first difficulty was that the two sets of mnemonic aids (concrete and abstract jingles) may not have been equalized in all essential respects except for the manipulated variable of concreteness. Thus, in addition to not being similar in terms of length, the words may also have differed in degree of interitem association. For example, some words in the abstract jingle of our initial study, on analysis, seemed less common (e.g., review, spree, tithe, and chore) than those in the concrete jingle (e.g., shoe, tree, hive, and door). The words in the abstract jingle also seemed to be more 
interassociated than those in the concrete jingle, in particular, the words heaven, fate, divine, and amen.

A second difficulty in the initial experiment may have arisen in the possible interpretations of recall measures as a result of differences obtained in the amount of study time required in the initial stages (learning of the jingle and of the items) by high and low imagers. Since a group procedure with self-pacing was employed, the difference raised the possibility that study time and training conditions may have been confounded: i.e., with group study the slower $S$ dictated the amount of time spent on each item. Thus, the $\mathrm{S}$ who finished more quickly (e.g., the high imager in a group with the low imager) had more opportunity to rehearse the item, thereby affecting later recall.

In order to accommodate these deficiencies, a second experiment was conducted. The most important methodological changes were in the controls placed on the construction of the mnemonic aids and the administration of the tasks on an individual rather than group basis. In addition, the Ss in the initial experiment were undergraduates, while those in the second experiment were graduate students.

Within this context, it is important to note that, despite methodological and $S$ differences in the initial (unreported) study and the one reported here, the results from the two experiments were the same in all essential respects. Accordingly, only the results of the second experiment, as a report of a replication, are presented in the subsequent sections.

\section{METHOD}

\section{Design}

High and low imagers first memorized a jingle comprising either concrete or abstract pegwords to serve as a mnemonic aid for later learning tasks. These two treatments were or thogonally crossed with two mediational modes, imaginal and verbal. All Ss memorized two word lists composed of concrete nouns and two lists composed of abstract nouns. There were 10 words in each list. Recall tests were administered immediately after learning a list. A complete recall test for all words was administered at the conclusion of the experiment. The overall design implied a mixed analysis of variance with three between-Ss variables (high or low imagery ability, concrete or abstract mnemonic aid, and imaginal or verbal mediator) and one within-Ss variable (concrete or abstract lists).

\section{Subjects}

The Ss were 88 graduate students enrolled in a summer course in educational psychology. Most had experience in teaching, and as a group, the age range was from 25 to 45 years. The Ss earned course credit for participation in the experiment. None had previously participated in a verbal learning study.

\section{Selection of Imagery Groups}

Initially, 285 Ss were administered the Space Thinking (Flags) Test (Thurstone \& Jeffrey, 1959), the spatial relations test of the Differential Aptitude Test Battery (Bennett, Seashore, \& Wesman, 1963), and the Memory for Designs Test (Graham \& Kendall, 1960). A factor score for each $S$ was obtained following the procedure described by Glass and Maguire (1966) in which the raw test scores are weighted by their respective factor loadings. These loadings were obtained from a factor analysis conducted previously and described in an earlier report by Di Vesta, Ingersoll, and Sunshine (1971). The 44 Ss with the highest factor scores were selected as the high imagers, and the $44 \mathrm{Ss}$ with the lowest scores were selected as low imagers. The Ss within each of these groups were randomly assigned to each of the experimental treatments. The only restriction in the random assignment of Ss was that there be an equal number of high and low imagers for each of the imaginal-mediator groups $(n=12)$ and for each of the verbal-mediator groups $(n=10)$.

Although factor scores were used to select Ss for each group, it may be helpful to know that the mean raw scores for the high imagery groups on the Flags Test, spatial relations test, and the Memory for Designs Test, respectively, were $121.80,87.71$, and 17.38 ; for the low imagery groups the means were $86.95,47.02$, and 14.92 , respectively. The means on a locally devised vocabulary test (administered as a test of verbal ability) were 20.72 for the high imagery group and 20.95 for the low imagerygroup.

\section{Materials}

\section{Learning Lists}

The 40 words used to construct the lists to be learned were selected from the concreteness (C), imagery (I), and meaningfulness (m) nornis reported by Paivio, Yuille, and Madigan (1968). Of the words selected, 20 were abstract and low on rated imagery and 20 were concrete and high on rated imagery. The two groups of words were approximately equivalent on the measure of $\mathrm{m}$. The means of the different attributes for the concrete (C) and abstract (A) lists, respectively, were: 6.54 and 2.90 for imagery ratings; 6.91 and 2.11 for concreteness ratings; and 6.13 and 5.50 for $\mathrm{m}$. Two lists of 10 concrete nouns in each were constructed by randomly selecting words from an initial list of 20 concrete nouns. Concrete List I comprised the words piano, candy, accordian, steamer, dress, elbow, mule, cigar, frog, macaroni. Concrete List II contained library, skull, tweezers, engine, corpse, building, headlight, pipe, leopard, nail. A similar procedure was employed in constructing two lists of 10 abstract nouns. Abstract List I was composed of adversity, belief, ego, irony, rating, hypothesis, emancipation, deceit, expulsion, ability. Abstract List II was composed of crisis, mercy, satire, magnitude, knowledge, perception, democracy, intellect, welfare, chance. The words in each list were presented in the order given above. None of these words was associated with related words in the jingle list.

\section{Jingle Words}

Forty-five words were selected from two rhyming dictionaries as a potential pool of items for the jingles (Stillman, 1965; Wood, 1936). For each word, independent ratings on 7-point bipolar scales ranging from 1 to 7 were obtained on imagery and concreteness as described by Paivio, Yuille, and Madigan (1968). A comparable scale was locally constructed for ratings of rhymability with the number in the jingle (e.g., one is a bun, etc.). Ratings on familiarity were obtained on a 5-point scale, and ratings of learning ease were based on a 9-point scale (Underwood \& Schulz, 1960; Spreen \& Schulz, 1966). Words to be used in the jingle were matched as closely as possible on all criteria. Nevertheless, it should be emphasized that perfect matches on all factors such as word length are virtually impossible because the availability of abstract rhyming words is severely limited. Accordingly, we had to resort to a word such as sine, which is a homophone of sign, and ken, which is an archaic word. We did not consider this to be a serious problem, since different words were used with the same results in the initial 
study and a procedure was employed to assure that Ss knew the meaning of each word.

The pegwords finally selected for the two jingles were rated in comparable ways on all measures except imagery and concreteness, the variables to be manipulated. The average ratings of familiarity, imagery, concreteness, rhymability, and learning ease for words in the concrete jingle were $4.5,5.9,6.6$, 1.6, and 7.8, respectively; for words in the abstract jingle the ratings were $4.3,2.7,2.4,1.4$, and 6.7 , respectively. The words used in the concrete jingle to rhyme with the numbers 1 to 10 were bun, shoe, tree, door, hive, sticks, leaven, gate, wine, hen. Those in the abstract jingle were fun, true, spree, chore, live, mix, heaven, hate, sine, ken.

Prior to the experiment, E read each pegword of the mnemonic for a given condition together with its definition. At the end of the reading, the $\mathrm{E}$ asked if any definition needed to be reviewed. Only a very few Ss chose to raise questions about these definitions.

\section{Procedure}

The experimental tasks were administered individually. The first instructions provided an overview of the purpose of the experiment and the steps to be followed when recording associations in the verbal or imaginal modes.

Second, during a study trial, each item (with which the $S$ had been familiarized) in the jingle was presented orally to the $S$ at a $1-\sec$ rate. There followed a $1-\mathrm{min}$ recall trial during which the $S$ attempted to recall and recite the entire jingle. This procedure was repeated until $\mathrm{S}$ achieved two errorless trials.

Third, E read aloud one of two sets of instructions depending upon the treatment being administered, i.e., a given $S$ was instructed to employ either imaginal or verbal mediation in performing the tasks. In the use of imaginal mediation, Ss were instructed to connect, with a mental picture or image, each noun in the list to be learned with the jingle noun in the corresponding serial position and to record immediately his connection by drawing a picture, however crude it might be. In the verbal mediation condition, Ss were instructed to form a sentence or phrase relating each noun in the list to the jingle noun in the corresponding serial position and immediately to record his connection in verbal form.

Fourth, these instructions were followed by the administration of two concrete noun pairs and one abstract noun pair for practicing the use of the jingle and mediational mode.

Fifth, the experimental lists were then administered by self-paced presentations, that is, a noun in the learning list was presented orally by $E$ and then $E$ waited for the $S$ to record his hookup response (either verbally or pictorially) before the next noun was presented. In both modes, latency was recorded by $\mathrm{E}$. The measure of latency was the time taken to produce the mediator, that is, by the time lapse between the time the list noun was presented and the time $S$ began to write or draw.

Following a single presentation of each experimental list, the $S$ attempted to recall, in serial order, each word (immediate recall) in the list. After the recall test for the fourth list, there was a 2 -min rest period. Then the $S$ was required to recall all of the words from the four lists that were in the first position, all of the words from the four lists that were in the second position, and so on to the words in the 10 th position (delayed recall). This recall trial was used to determined how many of the 40 words $S$ could retrieve, in order of position, from all lists at the conclusion of the experiment.

The presentation of the four lists were counterbalanced among Ss by the use of a simple Latin square to minimize the possible effects on recall of the order in which the concrete and abstract lists were presented.

\section{RESULTS}

Mixed analyses of variance (see Design section above) were made of the following measures: (a) latencies in arriving at an association between the mnemonic aid and the words in the list to be memorized; (b) total errors, separately for concrete and abstract lists, on the immediate recall tasks; and (c) total errors on the final (delayed) recall trial. ${ }^{1}$ All comparisons between simple means were made via a priori $t$ tests employing the appropriate error term(s) from the analysis of variance. A summary of the means based on these measures is presented in Table 1.

The mean number of trials (including criterial trials) taken to learn the concrete jingle was 2.8 ; to learn the abstract jingle it was 3.0. Since the time taken to learn the two jingles was not significantly different during acquisition, it was assumed that they were equally available when $\mathrm{S}$ had to generate a mnemonic system and later when he had to recall the mnemonic aid for retrieving list words.

\section{Latency}

The analysis of latency scores yielded a significant main effect due to mediation mode $[F(1,80)=18.30$, $\mathrm{p}<.001]$, indicating that imaginal mediation required more time $(\overline{\mathrm{X}}=196.70 \mathrm{sec})$ than verbal mediation $(\overline{\mathrm{X}}=$ $115.11 \mathrm{sec})$. The main effect due to lists $[F(1,80)=$ $17.66, \mathrm{p}<.001]$ must be qualified by the significant interaction between mediation mode and kind of lists $[F(1,80)=10.71, p<.01]$. This interaction was due to no significant difference $[\mathrm{t}(80)=0.42, \mathrm{p}>.10]$ between the concrete list $(\overline{\mathrm{X}}=111.85 \mathrm{sec})$ and the abstract list $(\overline{\mathrm{X}}=118.38 \mathrm{sec})$ when verbal mediators were used and a significant difference $[\mathrm{t}(80)=5.33$, $\mathrm{p}<.001]$ between time taken for the abstract list $(\overline{\mathrm{X}}=$ $234.65 \mathrm{sec}$ ) and the concrete lists $(\overline{\mathrm{X}}=158.73 \mathrm{sec}$ ) when imaginal mediators were used. It should be noted that all other simple comparisons of means comprising this interaction were significant $(p<.05)$. For example, the difference between verbal mediators $(\overline{\mathrm{X}}=111.85 \mathrm{sec})$ and imaginal mediators $(\overline{\mathrm{X}}=158.73 \mathrm{sec})$ with the concrete list was significant $[\mathrm{t}(80)=2.15, \mathrm{p}<.05]$ and the difference between concrete $(\overline{\mathrm{X}}=158.73 \mathrm{sec})$ and abstract lists $(\overline{\mathrm{X}}=234.65 \mathrm{sec})$ when using imaginal mediation was significant $[\mathrm{t}(80)=5.31, \mathrm{p}<.001]$.

These results indicate only that imaginal mediators required more effort or were generally more difficult (especially with abstract words) than verbal linkages. Important for interpretation of the data which follow was the finding of no significant differences in latency due to imagery ability or its interaction with other variables.

\section{Errors: Immediate Recall}

The analysis of variance of number of errors made by all groups on the immediate recall tests yielded $\mathrm{F}(1,80)$ $=5.78, \mathrm{p}<.02$ for the main effect due to imagery ability and $F(1,80)=32.08, p<.001$ for the main effect due to lists. 
Table 1

Summary of Means and Standard Errors of the Means for Each Experimental Group

\begin{tabular}{|c|c|c|c|c|c|c|c|c|c|c|c|}
\hline \multirow{3}{*}{\multicolumn{2}{|c|}{$\begin{array}{l}\text { Kind of Mediator, } \\
\text { Imagery Ability, and } \\
\text { Dependent Variable }\end{array}$}} & \multicolumn{4}{|c|}{ Concrete Mnemonic } & \multicolumn{4}{|c|}{ Abstract Mnemonic } & & \\
\hline & & \multicolumn{2}{|c|}{ Concrete List } & \multicolumn{2}{|c|}{ Abstract List } & \multicolumn{2}{|c|}{ Concrete List } & \multicolumn{2}{|c|}{ Abstract List } & \multicolumn{2}{|c|}{ Row Totals } \\
\hline & & Mean & SE & Mean & $\mathrm{SE}$ & Mean & $\mathrm{SE}$ & Mean & $\mathrm{SE}$ & Mean & $\mathrm{SE}$ \\
\hline \multicolumn{12}{|c|}{ Imaginal Mediator } \\
\hline High Imagers & $\begin{array}{l}\mathrm{L}^{*} \\
\mathrm{I}^{*} \\
\mathrm{~F}^{*}\end{array}$ & $\begin{array}{r}131.42 \\
2.25 \\
5.17\end{array}$ & $\begin{array}{r}15.99 \\
0.59 \\
0.69\end{array}$ & $\begin{array}{r}213.67 \\
4.08 \\
7.62\end{array}$ & $\begin{array}{r}31.66 \\
0.77 \\
0.90\end{array}$ & $\begin{array}{r}191.42 \\
2.92 \\
3.58\end{array}$ & $\begin{array}{r}31.54 \\
0.48 \\
0.56\end{array}$ & $\begin{array}{r}307.83 \\
4.00 \\
6.42\end{array}$ & $\begin{array}{r}65.64 \\
0.60 \\
0.87\end{array}$ & $\begin{array}{r}211.08 \\
3.31 \\
5.71\end{array}$ & $\begin{array}{r}24.33 \\
0.38 \\
0.45\end{array}$ \\
\hline Low Imagers & $\begin{array}{l}\mathrm{L} \\
\mathrm{I} \\
\mathrm{F}\end{array}$ & $\begin{array}{r}139.58 \\
4.67 \\
10.17\end{array}$ & $\begin{array}{r}34.47 \\
1.02 \\
1.54\end{array}$ & $\begin{array}{r}199.42 \\
8.17 \\
11.08\end{array}$ & $\begin{array}{r}53.27 \\
1.45 \\
1.47\end{array}$ & $\begin{array}{r}172.50 \\
5.67 \\
8.33\end{array}$ & $\begin{array}{l}6.98 \\
0.79 \\
0.92\end{array}$ & $\begin{array}{r}217.67 \\
8.25 \\
13.50\end{array}$ & $\begin{array}{r}19.40 \\
0.95 \\
1.13\end{array}$ & $\begin{array}{r}182.29 \\
6.69 \\
10.77\end{array}$ & $\begin{array}{r}21.90 \\
0.72 \\
1.02\end{array}$ \\
\hline Verbal Mediator & $\begin{array}{l}\mathrm{L} \\
\mathrm{I} \\
\mathrm{F}\end{array}$ & $\begin{array}{r}132.00 \\
4.90 \\
7.10\end{array}$ & $\begin{array}{r}17.91 \\
1.65 \\
1.97\end{array}$ & $\begin{array}{r}141.70 \\
5.50 \\
9.70\end{array}$ & $\begin{array}{r}20.66 \\
1.28 \\
1.92\end{array}$ & $\begin{array}{r}107.30 \\
3.70 \\
6.50\end{array}$ & $\begin{array}{r}10.84 \\
0.49 \\
0.76\end{array}$ & $\begin{array}{r}106.20 \\
6.00 \\
11.10\end{array}$ & $\begin{array}{r}12.29 \\
0.80 \\
1.23\end{array}$ & $\begin{array}{r}121.80 \\
5.03 \\
8.60\end{array}$ & $\begin{array}{r}11.02 \\
0.66 \\
0.80\end{array}$ \\
\hline Low Imagers & $\begin{array}{l}\text { L } \\
\text { I } \\
\text { F }\end{array}$ & $\begin{array}{r}93.40 \\
1.80 \\
4.00\end{array}$ & $\begin{array}{r}11.73 \\
0.63 \\
1.02\end{array}$ & $\begin{array}{r}109.90 \\
4.70 \\
7.40\end{array}$ & $\begin{array}{r}13.37 \\
1.02 \\
1.44\end{array}$ & $\begin{array}{r}114.70 \\
4.50 \\
6.80\end{array}$ & $\begin{array}{r}11.78 \\
0.60 \\
1.50\end{array}$ & $\begin{array}{r}115.70 \\
5.10 \\
10.50\end{array}$ & $\begin{array}{r}14.27 \\
0.96 \\
1.90\end{array}$ & $\begin{array}{r}108.43 \\
4.03 \\
7.18\end{array}$ & $\begin{array}{l}8.39 \\
0.50 \\
0.96\end{array}$ \\
\hline
\end{tabular}

${ }^{*} L=$ latency, $I=$ errors on initial recall tests, and $F=$ errors on final recall test.

The interaction (see row means in Table 1) between imagery ability and mediation mode yielded $F(1,80)=$ $14.29, \mathrm{p}<.001$ : High imagers made fewer errors $(\bar{X}=$ 3.31) than did low imagers $(\overline{\mathrm{X}}=6.69)$ when the imaginal mediator was used $(t=3.06, p<.01)$. The difference between the high $(\overline{\mathrm{X}}=5.03)$ and low $(\overline{\mathrm{X}}=4.03)$ imagers was not significant $(\mathrm{t}=0.83, \mathrm{p}<.05)$ when verbal mediators were used. Furthermore, low imagers made significantly fewer errors when using verbal mediators $(\overline{\mathrm{X}}$ $=4.03)$ than when using imaginal mediators $(\overline{\mathrm{X}}=6.69)$ $[\mathrm{t}(80)=2.30, \mathrm{p}<.05]$.

\section{Errors: Delayed Recall}

An analysis of variance of the mean number of errors made on the final recall test yielded $F(1,80)=6.83$, $\mathrm{p}<.01$ for the main effect due to imagery ability and $F(1,80)=64.88, p<.001$ for the main effect due to lists. The interaction between the kind of mnemonic and lists was also significant $[F(1,80)=5.04, p<.05]$. This interaction indicated only that the difference in numbers of errors between recall of the concrete and abstract lists was greater when the abstract mnemonic was used than when the concrete mnemonic was used (see Table 1).

The finding of primary interest in the analysis of delayed recall error iscores was the interaction between imagery ability and kind of mediator which yielded $\mathrm{F}(1,80)=15.96, \mathrm{p}<.001$. The results are similar to those obtained on the immediate recall tests: Thus, the interaction indicates that, when using imaginal mediators, high imagers made significantly $[t(80)=3.27$, $p<.01]$ fewer errors $(\bar{X}=5.71)$ in delayed recall than did low imagers $(\overline{\mathrm{X}}=10.77)$. On the other hand, high imagers made more errors $(\overline{\mathrm{X}}=8.60)$ than low imagers $(\overline{\mathrm{X}}=7.18)$ when using verbal mediators, although the latter difference was not significant $[\mathrm{t}(80)=.84$, $\mathrm{p}>.10]$. Additionally, in this analysis, the low imagers using the verbal mediator $(\overline{\mathrm{X}}=7.18)$ made significantly $[t(80)=2.21, p<.05]$ fewer errors than those using the imaginal mediator $(\overline{\mathrm{X}}=10.77)$. However, while the recall of high imagers was directionally the same as in the immediate tests for imaginal $(\overline{\mathrm{X}}=5.71)$ and verbal $(\overline{\mathrm{X}}=$ $8.61)$ mediators, the difference in numbers of errors on the final recall test was not significant $[\mathrm{t}(80)=1.78$, $p>05]$.

\section{DISCUSSION}

The results of this study clearly demonstrate that rated imagery (i.e., concreteness) as a stimulus attribute, imaginal strategy as a mediational process, and imagery ability as an individual difference variable are related to performance (recall) on tasks involving imaginal processes. The finding that concrete nouns are acquired more easily than abstract nouns replicates the findings of earlier studies. Although at least one comparison of abstract and concrete nouns in pegword lists has been made (Paivio \& Yuille, 1969), the effects of the interaction of the variables examined in the present study have not been investigated, to our knowledge, in previous studies.

One of the unique findings in the present study was the interaction of imagery ability and kind of mediator. It can be reasoned that this interaction emerged as more significant than the interaction of imagery ability and type of pegword or type of list, since the difference between high and low imagers is in the process or strategies they prefer, or are able to use. Such processes are represented in the manipulation of mediators. Thus, it can be seen that high imagers are in "their own ball park" when using imaginal mediators. When required (i.e., forced) to use this strategy, they can perform effectively even with abstract materials. However, they may be unable to substitute profitably another strategy, 
such as a verbal one, when such strategies are necessary. Low imagers, on the other hand, probably are not considered as whatever is implied by the term "verbalizers" as sometimes suggested (Hollenberg, 1970; Stewart, 1965). The only clear ability that can be inferred about low imagers is that they do not excel in imagery ability and probably use other strategies to better advantage than the imagery one. Thus, in comparing the high with the low imager, we can assume from these data that the more critical variable is whether or not a strategy can be employed rather than on what kind of material, whether pegwords or stimulus materials, the strategy is used.

A major concern in conducting studies incorporating an individual difference variable should be the identification of tasks which demand the use of a single strategy to the exclusion of all other potential strategies. In the present study, the use of the imaginal mediator approached this goal, but not completely, since labels might have been employed by $\mathrm{S}$ in arriving at the links between the mnemonic aid and the list to be learned. There is no guarantee that the drawing of pictures or the production of sentences completely rules out the use of words or pictures, respectively. Alternatively, it may be possible in future studies to devise task materials that can be processed by only one method to the exclusion of the other, thereby taxing the ability in question.

Nevertheless, the overall results of this study indicate that whatever has been measured by the battery of "imagery" tests clearly generalizes to the processing of information by the learner. That this implication may be specific to imagery is further corroborated by the low correlation $(r=.26)$ between imagery factor scores and the Scholastic Aptitude Test scores of Ss from a comparable pool of Ss (Di Vesta, Ingersoll, \& Sunshine, 1971).

In summary, the present study indicates that any relation found between individual differences and treatments may be in the ability of the learner to deal with the task in general; his receptivity to, or preference for, certain kinds of stimuli over others; or his ability to employ certain strategies when he attacks a task or processes information. Stewart (1965) and Hollenberg (1970) both assumed that imagery ability affected the receptivity to stimuli. Accordingly, their investigations compared the acquisition and recall of learners when presented pictorial and verbal stimuli. Without minimizing the importance of presentation mode as a variable in learning, the present study suggests that the manner in which the learner processes the material, in terms of the task requirement (Yuille \& Paivio, 1967; Ernest \& Paivio, 1969, 1971), is as important as the effects of manner of presentation. For an understanding of the dynamics of learning, including the role of individual differences on performance, it may be more important.

\section{REFERENCES}

Bennett, G. K., Seashore, H. G., \& Wesman, A. G. Differential aptitude tests. (Grades 8-13 and adults.) New York: Psychological Corp., 1963.

Di Vesta, F. J., Ingersoll, G., \& Sunshine, P. A factor analy sis of imagery tests. Journal of Verbal Learning \& Verbal Behavior, $1971,10,471-479$.

Ernest, $\vec{C}$. H., \& Paivio, A. Imagery ability in paired-associate and incidental learning. Psychonomic Science, 1969, 15, 181-182.

Ernest, C. H., \& Paivio, A. Imagery and verbal associative latencies as a function of imagery ability. Canadian Journal of Psychology, 1971, 25, 83-90.

Glass, G. V., \& Maguire, T. O. Abuses of factor scores. American Educational Research Journal, 1966, 3, 297-304.

Graham, F. K., \& Kendall, B. S. Memory-for-Designs Test: Revised general manual. Perceptual \& Motor Skills, 1960, 11, 147-148.

Hollenberg, C. K. Function of visual imagery in the learning and concept formation of children. Child Development, 1970, 41, 1003-1015.

Paivio, A. Mental imagery in associative learning and memory. Psychological Review, 1969, 76, 241-263.

Paivio, A., \& Foth, D. Imaginal and verbal mediators and noun concreteness in paired-associate learning: The elusive interaction. Journal of Verbal Learning \& Verbal Behavior, $1970,9,384-390$.

Paivio, A., \& Yuille, J. C. Changes in associative strategies and paired associate learning over trials as a function of word imagery and type of learning set. Journal of Experimental Psychology, 1969, 79, 458-463.

Paivio, A., Yuille, J. C., \& Madigan, S. A. Concreteness, imagery, and meaningfulness values for 925 nouns. Journal of Experimental Psychology Monograph Supplement, 1968, 76(No. 1, Pt. 2).

Spreen, O., \& Schulz, R. W. Parameters of abstraction, meaningfulness, and pronounciability for 329 nouns. Journal of Verbal Learning \& Verbal Behavior, 1966, 5, 459-468.

Stewart, J. C. An experimental investigation of imagery. Unpublished doctoral dissertation, University of Toronto, 1965.

Stillman, F. The poet's manual and rhyming dictionary. New York: Crowell, 1965.

Thurstone, L. L., \& Jeffrey, T. G. Space thinking (Flags). Chicago: Education-Industry Service, 1959.

Underwood, B. J., \& Schulz, R. W. Meaningfulness and verbal learning. New York: Lippincott, 1960.

Wood, C. The complete rhyming dictionary and poet's craft book. New York: Halcyon House, 1936,

Yuille, J. C., \& Paivio, A. Latency of imaginal and verbal mediators as a function of stimulus and response concreteness-imagery. Journal of Experimental Psychology, $1967,75,540-544$.

\section{NOTE}

1. Unweighted means and equal ns analyses of variance were calculated for these data at the suggestion of a consulting editor. Very similar results were obtained for all effects; hence, the reported values of $F$ are from the original analyses with weighted means.
(Received for publication July 6, 1973; revision received October 15, 1973.) 